\title{
Lateral preference for identical geometric forms: II. Retardates
}

IRMA R. GERJUOY AND JOHN J. WINTERS, JR. JOHNSTONE TRAINING AND RESEARCH CENTER, BORDENTOWN, NEW JERSEY

Adolescent educable retardates made size discriminations between pairs of equal-sized geometric forms presented tachistoscopically (Experiment I) or manually with unlimited exposure(Experiment II). There was no side preference under tachistoscopic presentation. Under unlimited exposure Ss showed a strong preference to choose the right-side stimulus as the larger (59.1\%). Normals, from previous studies, had a preference to perceive the right-hand stimulus as larger under both conditions.

In a binary-choice task, Ss' responses may be either stimulus-determined or response-determined, depending upon the difficulty of the discrimination and the instructional set (Tune, 1964). To take the extremes, when the two stimuli are easily discriminable, $S$ will learn to respond to the relevent cues of the stimuli; on the other hand, when the two stimuliare indiscriminable, or $\mathrm{S}$ has been given a guessing game set, his responses will reflect his own response preferences or his sequential response tendencies. The most popular response tendencies are a position preference for the right-hand stimulus and a tendency to alternate responses above chance. Since response preferences are complementary to sequential tendencies, such as alternation, any increase in one preference must result in a decrease in the other.

It has been found previously that $S$ variables are as important as experimental variables in the relative sizes of these tendencies. Iwahara (1959) reported that in a binary-choice guessing-game task adult Ss had a greater right-side preference than children, and that children alternated significantly more than adults. The results of a study by Gerjuoy and Gerjuoy (1965) indicated that retarded adolescents, as well as normal pre-adolescents, alternated significantly more than normal adults. In a related study, Gerjuoy and Winters (1965) replicated this finding and, in addition, found that normal adults had a larger right-side preference than the lower MA groups. In the studies cited the mode of response was motoric.

A tendency for normal adults to judge the right-side stimulus of two equal-sized geometric forms as the larger has also been demonstrated (Winters \& Gerjuoy, 1965; Winters \& Gerjuoy, 1966). The effects of lateral preference on perceptual choice response were sustained over 10 and 20 trials, whereas this preference decreased after the first trial in the non-perceptual tasks. Perceptual enlargement of the right-side figure was found under both tachistoscopic presentation and unlimited exposure of simultaneously presented identical figures.
Although the right-side preference has been consistent over a wide variety of tasks with normal adults and adolescents, this has been the case with neither normal pre-adolescents nor retarded adolescents. In the studies utilizing these populations, only a very transient rightside preference has been found. An alternation tendency has been more pronounced.

The purpose of the present two studies was to replicate the perceptual studies just cited, using adolescent educable retardates as the $S$ population. If a right-side perceptual preference is related to MA, then retardates should not exhibit preferences in these tasks. If this preference is a function of $\mathrm{CA}$, they should show as strong a perceptual preference as equal CA normals in both tasks. If, however, retardates show an attentional deficit with the short exposure time, they may show no preference under tachistoscopic presentation, but still show a strong preference under unlimited exposure. In the event that retardates do not exhibit a right-side perceptual preference, they should adopt a guessing-game set and alternate their responses above chance.

\section{Method}

\section{EXPERIMENT I. TACHISTOSCOPIC EXPOSURE}

Subjects. The Ss were 96 high grade retardates from the Johnstone Training and Research Center $(\overline{\mathrm{CA}}=$ 19.10, $\sigma=1.33$ yr.; $\overline{\mathrm{IQ}}=62.37, \sigma=9.14$ ). Equal numbers of Ss were randomly assigned to each of four treatments, the combinations of "larger" or "smaller" instructions with $10 \mathrm{sec}$. or $30 \mathrm{sec}$. intertrial interval. Sixteen additional Ss were discarded for failure to respond on one or more trials, for responding with both hands simultaneously or for making extra responses between stimulus presentations.

Apparatus. The stimuli were presented in a modified Gerbrands tachistoscope. Two telegraph keys, placed side by side $5-1 / 2$ in. apart below the eyepiece of the tachistoscope, were used as the response manipulanda.

Stimulus materials. The stimuli consisted of five identical pairs of geometric figures: triangles, circles, squares, semicircles, and diamonds.

Procedure. Before S was presented with the stimuli, he was dark-adapted for $3 \mathrm{~min}$., shown a large black square outline, and instructed to adjust his head until he could see all four sides and keep his head in that position. This procedure was used to ensure that $S$ was viewing the entire stimulus field. Half the Ss were instructed to push the button on the side of the larger 
shape, half were instructed to respond to the smaller shape. Each stimulus pair was exposed twice, upright and inverted, for $0.8 \mathrm{sec}$. The intertrial interval was $10 \mathrm{sec}$. for half the Ss and $30 \mathrm{sec}$. for the remaining $\mathrm{Ss}$.

\section{Results}

Ss did not exhibit any side preference. There were no significant differences among the responses of the four treatment combinations.

Under the more massed presentations (10 sec.) retardates alternated above chance $\left(X^{2}=4.48, p<.05\right)$; under distributed trials ( $30 \mathrm{sec}$.), however, their alternations did not differ from chance.

\section{EXPERIMENT II. UNLIMITED EXPOSURE}

\section{Method}

Subjects. The Ss were 60 institutionalized adolescent educable retardates, chosen at random from the 96 retarded Ss of Experiment I. Thirty Ss were randomly assigned to each of two instructional conditions.

Stimulus materials. The stimulus cards were the same as those used in the previous study with high school normals (Winters \& Gerjuoy, 1965). They consisted of 10 white 4 in. $x 6$ in. cards with pairs of identical geometric figures. The figures used were five pairs of circles, two pairs of hexagons, two pairs of squares, and one pair of triangles. The sets of figures varied in size. The centers of the figures were 2 in. from the bottom of the cards. Each pair of figures was centered on the card horizontally with approximately 0.5 in. between the two figure outlines. Figures were drawn in black India ink with the outlines $0.5 \mathrm{~mm}$ wide.

Procedure. All Ss were presented the 10 cards in the same order; the cards were then inverted and again presented in the same order to control for any objective differences within pairs. During the initial 10 presentations, half the Ss were instructed to determine which was the larger stimulus in each pair; the remaining Ss were instructed to determine which was the smaller stimulus in each pair. For the second 10 presentations, the opposite instructions were given. In other words, all Ss were run under both instructional conditions.

E presented the cards manually to S. E pointed to one stimulus in each pair and asked $S$ if it were the larger (smaller). S responded with "yes" or "no." The verbal response was chosen to avoid confounding any perceptual preference with a motor preference.

Six separate orders of E's pointing were prepared. They were random with the restrictions that three orders started with the left stimulus and three with the right stimulus; $E$ pointed to an equal number of left and right stimuli within each order; and no more than three consecutive pointings were to the same side either within or between the two halves of the experiment. These restrictions were included to reduce the effects of response biases other than the bias to perceive the stimulus on one side as the larger.

As soon as $\mathrm{S}$ made a response to a stimulus card, he was immediately presented with the next card. No attempt was made to keep the exposure time or the intertrial interval constant within or between Ss. Ss generally responded within a few seconds.

$S$ was given the hole-in-card test (Harris, 1958) and was required to write his name to indicate his preferred eye and hand.

At the conclusion of the task, $S$ was given a candy or cigarette reward.

\section{Results}

Ss exhibited a significant affirmative response bias. $59.1 \%$ of all responses were "yes" $\left(\mathrm{X}^{2}=39.6, \mathrm{p}<.001\right)$ indicating that Ss had a tendency to agree with $E$.

Although Ss did net demonstrate a preference to call one side or the other larger on the first trial, they showed a strong preference $(72 \%)$ to see the right side as the larger on the second trial $\left(X^{2}=19.38\right.$, $p<.001$ ). Over all 20 trials, $59.1 \%$ of all responses indicated the right side as larger $\left(X^{2}=39.6, p<.001\right)$.

There were no differences in response bias between males and females, nor any differences between the two instructional conditions. Ss under "larger" instructions tended to see the right-side stimulus as the larger while Ss under "smaller" instructions tended to see the left-side stimulus as the smaller. There were no differences in side preference between the first and second halves of the task for all Ss combined nor for either instructional group.

Ss tended to perceive the right-side stimulus as the larger regardless of which of the two stimuli on each card was presented on the right. Thus, there were no objective differences within pairs of figures. Analysis of the individual stimulus pairs yielded no differences among pairs of stimuli in tendencies to elicit perceptions of the right-hand stimulus as the larger.

The perception of the right-hand stimulus as the larger was as great for retardates as for the High School normals of the previous study (Winters \& Gerjuoy, 1965).

$\mathrm{Ss}^{\circ}$ response preferences were unrelated to their handedness or eyedness.

\section{Discussion}

When Ss perceive a subjective difference between two stimuli, even when they are objectively the same size, they view the task as a discrimination problem. This was the case with normal Ss. Retardates, on the other hand, did not perceive differences between the stimuli under the tachistoscopic presentation of Experiment I. Therefore, they apparently viewed the task as a guessing game. When the trials were more massed (10 sec. vs. $30 \mathrm{sec}$ ) retardates alternated above chance. When the intertrial interval was $30 \mathrm{sec} .$, alternation was reduced to chance. Iwahara (1959) also found that increasing the intertrial interval reduced alternation. The longer time interval may have interfered with the memory trace from the previous response and, con- 
sequently, reduced the amount of alternation. If the trials had been even more massed, as in binary-choice paper and pencil tasks (Gerjuoy \& Gerjuoy, 1965; Gerjuoy \& Winters, 1965), Ss might have alternated as much as in the latter tasks. Further, with paper and pencil tasks, Ss have continuous access to their previous responses, which increases alternation.

Since the retarded Ss had a response preference under unlimited exposure but not under tachistoscopic exposure, such a preference cannot be simply a function of either MA or CA. The difference in the results of the two studies may, however, be related to slower processing of information in the retardate than in the normal; under short exposures retardates are unable to process the incoming information as completely as normals. This view is consistent with Spitz's hypothesis (1963) that cortical changes take place more slowly in the retardate. The fact that retardates do not differ from normals under unlimited exposure time while they do differ under short tachistoscopic exposure lends support to the hypothesis that the primary process underlying the right-side enlargement with short exposures is physiological rather than experiential. Retardates of the same age as normals should have had equivalent experience in a "right-handed" world. On the other hand, it is likely that the primary process underlying the right-side enlargement with unlimited exposure is experiential, since the extended exposure time allows for the elicitation of past experiences which foster these subjective responses, whereas, the tachistoscopic exposure allows time for only a purely perceptual process. Therefore, the right-side preference of Experiment II may be due to the predominance of the experiential factor over any physiological component.

Finally, it should be noted that perceptual preferences are stronger and more persistent than motor preferences even for normal adults. As indicated in previous studies, when a motor choice was predominant or the only choice available to $S$, this preference was less pronounced. Although retardates were found to have a strong perceptual preference in Experiment II, they have never exhibited more than a slight right-side motor preference under any experimental conditions.

\section{Roterences}

Gerjuoy, I. R., \& Gerjuoy, H. Binary-choice sequences of retardates, normal children, and college students under random- and pattern-set instructions. Amer. J. ment. Defic., 1965, 69, 854859 .

Gerjuoy, I. R., Winters, J. J., Jr. Binary-choice responses of retardates, normal children, and college students to similar or dissimilar stimuli. Amer. J. ment. Defic., 1965, 70, 474-477.

Harris, A. J. Harris tests of lateral dominance: Manual of directions for administration and interpretation. (3rd ed.) New York: Psychological Corporation, 1958.

Iwahara, S. Studies of spontaneous alternation in human subjects: III. A developmental study. Jap. psychol. Res., 1959, 1, 1-8.

Spitz, H. H. Field theory in mental deficiency. In N. R. Ellis (Ed.), Handbook of mental deficiency: Psychological theory and re search. New York: McGraw-Hill, 1963. Pp. 11-40.

Tune, G. S. Response preferences: A review of some relevant literature. Psychol. Bull., 1964, 61, 286-302.

Winters, J. J., Jr, \& Gerjuoy, I. R. Gamma movement: Field brightness, series, and side of the standard. Psychom. Sci., 1965, 2, 273-274.

Winters, J. J., Jr., \& Gerjuoy, I. R. Lateral preference for identical geometric forms: I. Normals. Percept. \& Psychophys., 1966, 1, 101-103.

(Received in the Editorial office February 11, 1966.) 